\title{
Schnitzler syndrome: clinical features and histopathology
}

\author{
This article was published in the following Dove Press journal: \\ Pathology and Laboratory Medicine International \\ 16 June 2015 \\ Number of times this article has been viewed
}

\author{
David Dingli ${ }^{1,2}$ \\ Michael J Camilleri ${ }^{3}$ \\ 'Division of Hematology, Department \\ of Internal Medicine, ${ }^{2}$ Department of \\ Molecular Medicine, ${ }^{3}$ Department of \\ Dermatology, Mayo Clinic, Rochester, \\ MN, USA
}

\begin{abstract}
Schnitzler syndrome is a rare and underrecognized syndrome characterized by chronic urticaria, a monoclonal protein, and a variety of other symptoms, including fever, bone pain, organomegaly, and evidence of an acute phase response. Biopsy of an involved area of the skin shows a neutrophilic infiltrate without evidence of vasculitis or hemorrhage. Although the etiology of the syndrome is unknown, current evidence suggests this is an autoinflammatory syndrome. Recognition of this syndrome is critical since it is highly responsive to anakinra.

Keywords: neutrophilic urticarial dermatosis, autoinflammatory syndrome, monoclonal gammopathy, neutrophilic dermatosis, anakinra
\end{abstract}

\section{Introduction}

In the early 1970s, the French dermatologist Liliane Schnitzler described a novel clinical syndrome characterized by chronic urticaria in association with a monoclonal IgM (less likely IgG) paraprotein, which ultimately was to bear her name. ${ }^{1,2}$ Subsequently, work by Lipsker ${ }^{3}$ and de Koning et $\mathrm{al}^{4}$ as well as the Schnitzler syndrome study group ${ }^{5}$ led to a more standardized definition of the syndrome culminating in the development of the Strasbourg criteria for diagnosis (Table 1). Typically, patients are in the sixth decade of their life at diagnosis (ranging from 30 to 76 years in one series), and men are affected slightly more than women $(1.2: 1) .{ }^{6}$ Although the syndrome is well defined, unfortunately, it is almost certainly underrecognized, with the consequence that there tends to be a considerable delay, often of 5-6 years between the onset of symptoms and proper diagnosis that ultimately leads to correct therapy that can literally transform the life of patients with this syndrome., ${ }^{3,5-7}$

Apart from the urticarial rash, other clinical features that are often present include malaise, fever, myalgia, arthralgia or bone pain, and enlarged lymph nodes. Symptoms of peripheral neuropathy may also be present (Table 2).

\section{Clinical features The rash}

The urticarial eruption is typically chronic and recurrent and generally difficult to treat since it is either resistant to therapy or relapses fairly quickly once therapy is stopped (at least until the proper diagnosis is established). The skin rash consists of a pale rosecolored macular eruption that sometimes also develops into raised papules and plaques (Figure 1A). These skin lesions may be associated with mild-to-moderate pruritus, and they generally resolve spontaneously within 24 hours without any scarring. The trunk
Correspondence: David Dingli Mayo Clinic, 200 First Street SW, Rochester, MN 55905, USA

$\mathrm{Tel}+\mathrm{I} 5072843417$

$\mathrm{Fax}+\mathrm{I} 5072664972$

Email dingli.david@mayo.edu
Pathology and Laboratory Medicine International 20I5:7 39-46 39

Dovepress

(c) (i) (5) 2015 Dingli and Camilleri. This work is published by Dove Medical Press Limited, and licensed under Creative Commons Attribution - Non Commercial (unported, v3.0) http://dx.doi.org/10.2147/PLMI.S69414 
Table I Strasbourg diagnostic criteria for Schnitzler syndrome

Obligate criteria (both required)
Chronic urticarial rash
Monoclonal IgM or IgG
Minor criteria
Recurrent fever $\left(>38^{\circ} \mathrm{C}\right.$ and unexplained)
Evidence of abnormal bone remodeling with or without bone pain
(abnormal bone scintigraphy, MRI, or elevated bone alkaline
phosphatase)
A neutrophilic dermal infiltrate on skin biopsy
Leukocytosis (neutrophils $>10,000 / \mu L)$
Elevated C-reactive protein (30 $\mathrm{mg} / \mathrm{L})$
Definite diagnosis
Both obligate criteria and
At least two minor criteria if IgM
At least three minor criteria if IgG
Probable diagnosis
Both obligate criteria and
At least one minor criterion if IgM
At least two minor criteria if IgG

and proximal extremities are mainly affected, while the face, neck, hands, and feet are very rarely affected by the rash. The best description of the rash is that of a neutrophilic urticarial dermatosis. ${ }^{8}$ Patients generally have ongoing lesions, and it is quite unusual for a patient to be free of any skin lesions for more than a few weeks at a time. The eruption can be exacerbated by exposure to cold or heat, alcohol consumption, or even stress. ${ }^{3}$ Angioedema is unusual and is seen in less than $10 \%$ of patients. ${ }^{3,6}$

\section{Fever}

In one series, $75 \%$ of patients developed fever that was associated with significant fatigue. ${ }^{6}$ The fever may be quite high, reaching $40^{\circ} \mathrm{C}$, although it rarely is associated with chills. ${ }^{7}$ There is no direct relationship between the fever and the skin rash, and in time, patients seem to get used to the recurrent pyrexia, perhaps due to the relative lack of associated chills, sweats $(25 \%)$, and rigors.

Table 2 Other features sometimes seen in Schnitzler syndrome

Arthralgia/arthritis
Organomegaly
Hepatomegaly
Splenomegaly
Lymphadenopathy
Peripheral neuropathy
Chronic refractory anemia
AA amyloidosis with nephrotic syndrome
Hearing loss
Nodular hyperplasia of the liver
Antiphospholipid antibody syndrome
Pseudoxanthoma elasticum

\section{Bone, joint, and muscle pain}

Musculoskeletal symptoms are common and seen in at least two-thirds of patients, if not more., ${ }^{4,6}$ In one series, arthralgias were reported in $68 \%$ of patients, while bone pain has been reported in $63 \%$. A systematic radiologic analysis of a cohort of 22 patients suggested that the most commonly affected bones were the distal femur and the proximal tibia followed by the innominate bone. ${ }^{9}$ Other bones that may be affected include the spine, humerus, talus, and fibula.

\section{Organomegaly}

On physical examination, apart from the rash, other notable findings can include pallor due to anemia (although this is generally mild). Palpable lymphadenopathy is found in approximately $45 \%$ of patients, while enlargement of the liver and spleen are less common and found in at most a third of patients..$^{3-6,10}$ The swollen lymph nodes are mainly found in the axillae and groin, with cervical adenopathy being less common. Nodes can vary in size and be up to several centimeters in diameter.

\section{Peripheral neuropathy}

Lipsker initially reported a low frequency of peripheral neuropathy in this syndrome (one patient), ${ }^{11}$ but a larger series from a single institution found a frequency of $56 \%$, although in most cases this was mild. ${ }^{6}$ This is perhaps not completely surprising given the association of IgM monoclonal gammopathy of undetermined significance (MGUS) with peripheral neuropathy due to the presence of anti-MAG and other antibodies with specificity to myelin antigens.

\section{Laboratory features and imaging Monoclonal protein}

The presence of a monoclonal protein in the serum is a sine qua non for the diagnosis of the syndrome. The initial description of the syndrome required the presence of monoclonal IgM in the serum, ${ }^{1,2}$ but there are anecdotal reports of monoclonal IgA and IgG that otherwise fit the clinical syndrome. ${ }^{7,12}$ The IgM is $\kappa$ light chain restricted in over $90 \%$ of patients. In one series, the ratio of $\kappa$ to $\lambda$ light chain restriction was $15: 1,{ }^{6}$ which is quite different from patients with IgM MGUS where the ratio is generally $56: 44$. This skewed distribution is highly statistically significant $(P=0.0044)$ and should serve to heighten the clinician to consider the possibility of Schnitzler syndrome as the diagnosis in patients with chronic urticaria. ${ }^{6}$ The serum M protein is small and generally below $1 \mathrm{~g} / \mathrm{dL}$. In one series, the median concentration of the monoclonal protein was $0.6 \mathrm{~g} / \mathrm{dL}$, although it can range from 0.5 to 

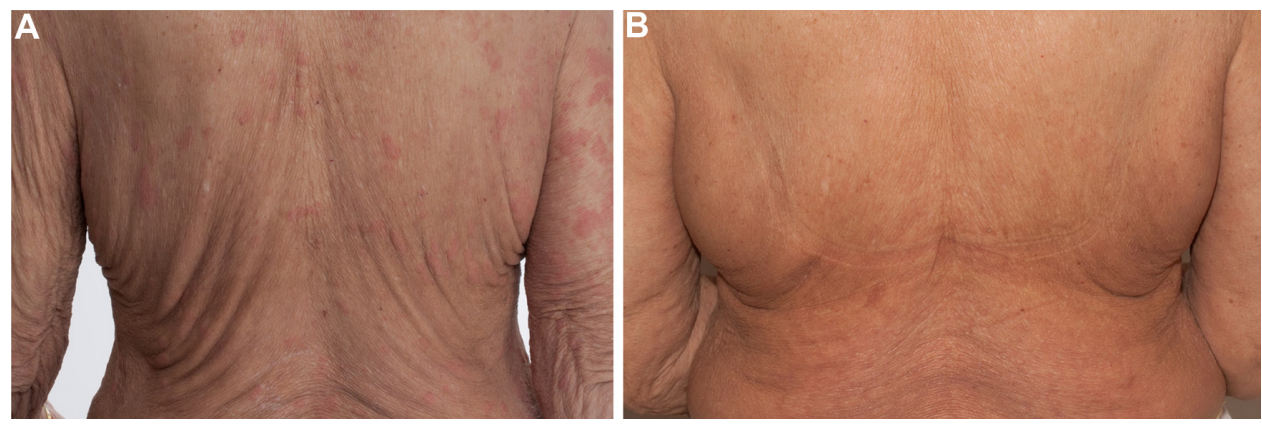

Figure I The typical rash of Schnitzler syndrome $(\mathbf{A})$ before initiation of therapy and (B) after the introduction of daily subcutaneous therapy with anakinra.

$3 \mathrm{~g} / \mathrm{dL} .{ }^{6}$ It is essential that if the syndrome is suspected, serum immunofixation is performed to detect very small amounts of monoclonal proteins that may not be measurable by standard serum protein electrophoresis techniques. In the majority of patients, the uninvolved immunoglobulins ( $\operatorname{Ig} A$ and $\operatorname{IgG}$ ) are normal. A monoclonal protein in the urine may be found in up to one-third of patients. The bone marrow may show a mild plasmacytosis, but normally the plasma cells constitute less than $10 \%$ (median of $4 \%$ ) of the bone marrow cellularity and may be polyclonal. ${ }^{3-6}$

\section{Additional laboratory abnormalities}

Most patients will have anemia at the time of diagnosis (median $\mathrm{Hb} 11.7 \mathrm{~g} / \mathrm{dL}$ ), and leukocytosis and thrombocytosis (both reactive) are also very common. The leukocytosis is invariably due to a neutrophilia and resolves promptly with the institution of definitive therapy. The sedimentation rate is generally quite high as is the $\mathrm{C}$-reactive protein. The ferritin level is normal and serves as an important clue that this is not adult-onset Still disease (AOSD). ${ }^{3-6}$ Complement levels are also normal, and if they are abnormal, one should suspect other diagnoses such as cryoglobulinemia, hypocomplementemic urticarial vasculitis, systemic lupus erythematosus, or perhaps a congenital deficiency of a complement component such as $\mathrm{C} 4 \mathrm{a} \cdot{ }^{3-5,13}$ It is the rare patient who has genuine Schnitzler syndrome and a low level of one of the complement components (usually $\mathrm{C} 4$ ). The $\mathrm{C} 1$ esterase inhibitor levels are generally normal.

\section{Imaging abnormalities}

The extent of radiologic findings depends on the modality used for imaging. The early reports included plain imaging of the skeleton, but techniques such as nuclear bone scanning, MRI, and CT or PET/CT appear to be substantially more sensitive. In one series with 22 patients, a radiologic abnormality was found in $64 \%$ of the patients, ${ }^{9}$ although in some series, the frequency of radiologic musculoskeletal findings was lower $(40 \%))^{14,15}$ The most common radiologic finding is bone sclerosis that most commonly affects the bone around the knee, with the femur somewhat more likely to be affected compared to the tibia. ${ }^{15}$ The pattern of sclerosis varies from trabecular thickening to patchy or confluent osteosclerosis. The sclerotic process always extends to involve the endosteum. Sometimes, the bone abnormality may be mixed with both sclerosis and lytic lesions. The metadiaphysis of long bones are generally affected, while isolated diaphyseal involvement likely should suggest another diagnosis since in one series of Schnitzler syndrome this was never observed. ${ }^{9}$ The innominate bone is also frequently abnormal on plain imaging, and the process tends to affect the medial and anterolateral aspects of the bone while the mid-superior iliac wing is spared, leading to a "V"-shaped area of osteosclerosis on frontal views of the pelvis.

Radionuclide bone scans are more sensitive than plain radiographs and show focal radiotracer uptake at the sites of bone sclerosis. Imaging findings with this technique are not always symmetric. However, nuclear imaging can be positive in the absence of abnormalities on conventional planar skeletal imaging. If cost considerations are an issue, one can argue that radionuclide bone imaging is the most cost-effective modality to evaluate the bone pain that is often present in this syndrome. ${ }^{9}$

If MRI is performed, this typically shows evidence of cortical thickening as well as medullary bone involvement in the absence of a tumor. ${ }^{15,16}$ Sometimes, the abnormality is restricted to the medulla with $\mathrm{T}_{2}$ hyperintensity.

PET/CT imaging is perhaps the most sensitive study in the radiologic evaluation of Schnitzler syndrome. It can demonstrate the presence of lymphadenopathy, hepatic or splenic enlargement, periosteal bone thickening as well as abnormal glucose uptake in the bone marrow (albeit at low levels) as well as uptake in the lymph nodes and spleen. In one series, no abnormality was missed by PET/CT when compared with other imaging modalities. PET/CT is also 
helpful in evaluating other potential diagnostic considerations such as lymphoma. ${ }^{9}$

\section{Pathophysiology}

The underlying pathogenesis of this enigmatic syndrome remains unclear, in part due to its rarity. To date, the allencompassing link between the monoclonal protein, rash, and the systemic inflammatory process has not been established. However, there are tantalizing clues. Although in some patients IgM deposits have been found in the skin, whether these are pathologic or a consequence of the inflammatory process is unclear. ${ }^{7,10,17}$ The presence of monoclonal IgM deposits is also not invariable, and in one series, this was only present in 3 of 13 patients tested. ${ }^{10}$ The skin rash is reminiscent of several inherited periodic fever syndromes, especially the autoinflammatory cryopyrin-associated periodic syndrome (CAPS) ${ }^{18,19}$ In the latter, a mutation in the NLRP3 is often found. ${ }^{19}$ More recently, subclonal mutations in this gene, restricted to granulocytes and monocytes, were reported in two patients (K435E and F523L) with rather severe Schnitzler syndrome. ${ }^{20}$ Moreover, two other patients with Schnitzler syndrome ${ }^{21}$ have been found to have the V198M variant of NLRP3, although it is not clear whether this variant is associated with any significant pathology since family members with this variant were also identified who were otherwise healthy. To date, there is no evidence of familial clustering of Schnitzler syndrome, suggesting that this is an acquired autoinflammatory syndrome rather than an inherited periodic fever syndrome. ${ }^{22}$ Moreover, the later age of onset (almost always in the fifth decade or later) argues against a genetic basis for the condition. The recent deep-sequencing studies hint at the tantalizing suggestion that perhaps an acquired mutation in NLRP3 may in part be responsible for the syndrome in some patients. However, this mutation is difficult to reconcile with the presence of a monoclonal protein that, as far as is known, does not occur in the CAPS syndrome.

What seems to be clear is that cytokines such as IL- 1 and perhaps IL-18 are important mediators of the syndrome. ${ }^{23-26}$ Although serum IL-1 levels are normal in patients with Schnitzler syndrome, isolated mononuclear cells from such patients secrete large amounts of IL-1 and IL-6 in response to lipopolysaccharide stimulation. ${ }^{25,27}$ In addition, the rapid, and often complete, response to therapy directed against IL-1 with anakinra, ${ }^{5}$ canakinumab ${ }^{28}$ and rilonacept ${ }^{29}$ clearly shows the central role that IL-1 plays in at least the manifestations of the disease. Although IL-1 is produced by monocytes and neutrophils, it has protean manifestations, including stimulation of chondrocytes, which may explain the joint symptoms that often plague these patients.

We would like to suggest a potential hypothesis that could explain the syndrome: a subclonal population of myeloid cells with an acquired mutation in NLRP3 leads to dysregulation of IL-1 production, and this can induce local B-cell proliferation (albeit at low levels). Such a mutation can arise in a multipotent progenitor cell that, therefore, will expand to include both granulocytes and monocytes. It is known that IL-1 $\beta$ can stimulate B-cells and plasma cells to grow. ${ }^{30}$ Perhaps, chronic stimulation of B-cells will lead to the emergence of a clonal population that expresses IgM or, less commonly, IgG, and subsequent mutations in the B-cells allow them to become independent of IL-1 signaling. The repeated observation that rituximab, which is often so effective at eliminating B-cell clones, has no impact on Schnitzler syndrome suggests that the monoclonal population of B-cells or plasma cells is not the main driver of the disease, although there is a paucity of data on CD20 expression on the clonal B-cell that produces the immunoglobulin. It is possible that the size of the NLRP3 mutant clone correlates with the severity of symptoms, and in the two patients reported to date, it was noted that mutations were only identified in the most severely affected patients. ${ }^{20}$ Another possible explanation would be that other acquired mutations in genes involved in regulation of IL-1 and IL-6 dynamics or the inflammasome are responsible for this syndrome.

What is against this hypothesis is that in children with the CAPS syndrome a monoclonal protein does not appear, although this could be due to effective early therapy that suppresses IL-1 stimulation of B-cells.

\section{Histopathology}

The histologic findings on biopsy of a typical skin lesion in patients with Schnitzler syndrome are distinct (Figure 2). A neutrophilic infiltrate with a variable density is found within the dermis and usually in a perivascular pattern. ${ }^{8,10}$ The neutrophils may be dispersed interstitially between the collagen bundles, together with leukocytoclasia. Eosinophils may also form a minor component of the infiltrate. Less common is a mononuclear cell infiltrate with perivascular inflammation. ${ }^{10}$ However, no evidence of vasculitis should be present, in contrast to patients with urticarial vasculitis. In addition, the lack of dermal edema distinguishes this syndrome from Sweet syndrome. ${ }^{3}$ Fibrinoid necrosis within blood vessels or dermal hemorrhage should not be present. ${ }^{7}$ Sometimes, the neutrophils can cluster around the sweat ducts with a pattern of eccrine hidradenitis. ${ }^{10}$ 

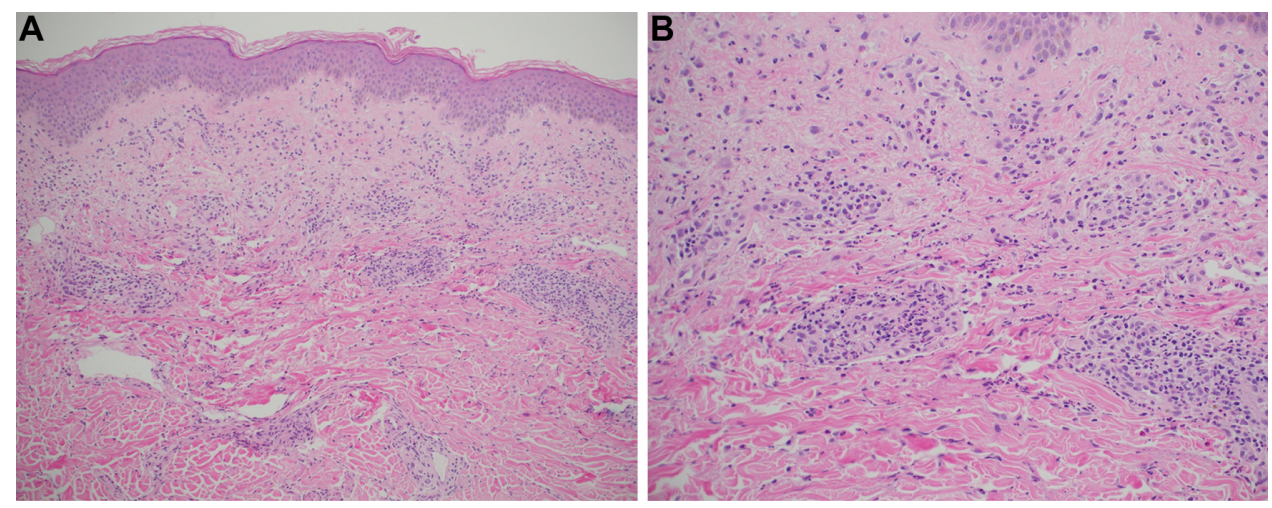

Figure 2 Typical histologic picture of a skin biopsy in a patient with Schnitzler syndrome at low $(\mathbf{A})$ and higher power (B) showing the perivascular neutrophilic infiltrate in the dermis.

When performed, immunofluorescence studies sometimes show the presence of vascular deposition of IgM, typically around the superficial dermal vessel. ${ }^{10}$ Less commonly, C3 deposits may also be found. Deposition of IgM and C3 within the granular basement membrane can also be seen..$^{10}$ Sometimes, the IgM is deposited at the junction between the dermis and epidermis, and there is evidence that these antibodies may target antigens present in the skin ${ }^{31,32}$ and, possibly, induce an inflammatory response leading to the skin lesions and symptoms. Sometimes, patients with the syndrome undergo lymph node biopsy, but in the absence of lymphoma, for which these patients are at risk, the findings tend to be nonspecific.

\section{Differential diagnosis}

The differential diagnosis of Schnitzler syndrome is broad and includes a number of inherited and acquired disorders. In general, these other diagnostic consideration can be easily excluded based on laboratory studies as well as an informative skin biopsy. Diagnostic considerations include Waldenstrom macroglobulinemia, hypocomplementemic urticarial vasculitis, AOSD, systemic lupus erythematosus, cryoglobulinemic vasculitis, $\mathrm{C} 1$ esterase inhibitor deficiency, chronic idiopathic urticaria, and several familial fever syndromes like CAPS such as Muckle-Wells syndrome or familial cold autoinflammatory syndrome, TRAPS (tumor necrosis factor receptor-associated periodic syndrome), and mevalonate kinase deficiency syndrome (also known as hyper-IgD syndrome).

Although AOSD may mimic Schnitzler syndrome with the urticarial rash, fever, arthralgias and anemia, leukocytosis and thrombocytosis, there are several clues that support the former diagnosis, including the very high ferritin levels that is typically seen in AOSD and elevated hepatic transaminases, both of which are not a feature of Schnitzler syndrome. In addition, many patients with AOSD would have a history of an initial pharyngitis that does not occur in Schnitzler syndrome. In Waldenstrom macroglobulinemia, the monoclonal protein is generally high, the lymphoplasmacytic component in the bone marrow is also considerable, and most patients would not have a leukocytosis, thrombocytosis, or joint pains. ${ }^{33}$ Patients with systemic lupus erythematosus will have positive serologies for antibodies against DNA or extractable nuclear antigens, and other diagnostic criteria that should enable relatively easy differentiation from Schnitzler syndrome. Similarly, patients with cryoglobulinemia generally would have Raynaud phenomenon and low complement levels that are generally not present in Schnitzler syndrome (the rare exception is the patient with a concomitant congenital complement component deficiency).

The familial fever syndromes such as CAPS generally present at an earlier age and are not associated with a serum monoclonal protein. ${ }^{18}$ One also has to note that an IgM monoclonal protein is not as common as IgG or IgA, and the combination of such a monoclonal protein (IgM) and chronic, resistant urticaria together with fever and systemic manifestations and evidence of inflammation should be highly suggestive of Schnitzler syndrome. ${ }^{3,6}$ Diagnosis of Schnitzler syndrome has been placed on a more secure footing by the publication of the "Strasbourg criteria", and these guidelines should be followed to establish the diagnosis in the absence of a specific diagnostic test for the syndrome.

\section{Therapy}

Schnitzler syndrome had a notorious reputation as being resistant to most agents including glucocorticosteroids, antihistamines, rituximab, and other agents. ${ }^{3,5}$ Although patients often responded to high doses of steroids, the responses tend 
to be incomplete and the disease often flares once they are tapered or discontinued. Immunosuppressive agents such as cyclophosphamide, azathioprine, and methotrexate are ineffective. ${ }^{3}$ Intravenous immune globulin or tumor necrosis factor- $\alpha$ blocking agents are also uniformly ineffective. ${ }^{3}$ Colchicine and dapsone can provide relief in mild cases and, in particular, help the cutaneous manifestations of the disease. ${ }^{7}$ Joint symptoms may sometimes respond to hydroxychloroquine. The quinolone antibiotic pefloxacin has been utilized with success in some patients. ${ }^{34,35}$ The mechanism of its action is not known, and the drug is not available in many countries, including the USA. Long-term use of this medication is associated with a risk of tendinopathy.

The therapeutic landscape for patients with this syndrome changed dramatically with the introduction of the IL-1 receptor antagonist anakinra that is given subcutaneously daily. The initial report in $2005^{36}$ was soon followed by many others as well as studies in short series of patients. ${ }^{6,37-41}$ Anakinra provides a rapid, dramatic, sustained and complete resolution of the rash and all the other symptoms as well as the normalization of the inflammatory markers (Figure 1B). The anemia resolves, and any reactive leukocytosis and thrombocytosis return to normal, but the monoclonal IgM remains detectable. Anakinra has a short half-life ( $\sim 6$ hours) and generally has to be taken daily, although some patients seem to be able to maintain disease control with alternate-day therapy. Most patients who skip dose(s) will rapidly experience resurgence of the symptoms, but they will however respond again if therapy is reinstituted. ${ }^{3}$ In patients who do not respond to the drug, the diagnosis of Schnitzler syndrome should be questioned. Sometimes, patients may respond to higher doses of anakinra. The drug is generally well tolerated apart from local injection site reactions. ${ }^{41}$ The patient should be monitored regularly for neutropenia while on this medication, especially soon after the introduction of the drug. In women who are contemplating pregnancy, the physician should have a discussion with the patient about the use of this medication during pregnancy. The US Food and Drug Administration rates anakinra as " $B$ " during pregnancy, which generally means that although there is no good evidence of risk, any studies that are available provide little information about the risks in human pregnancy associated with this medication. Some patients have also responded to therapy with canakinumab (anti-IL-1 $\beta$ ) ${ }^{28}$ or the IL-1 Trap (rilonacept), ${ }^{29}$ although the experience with the latter agents is much more limited. Experts also recommend consideration of the anti-IL-6 receptor monoclonal antibody tocilizumab in patients who fail therapy with the other agents, although evidence of benefit is also limited. ${ }^{42}$
The monoclonal protein should be followed up using standard guidelines for MGUS and patients monitored for the development of Waldenstrom macroglobulinemia, various types of non-Hodgkin lymphoma, IgM multiple myeloma, or amyloidosis. ${ }^{43}$

\section{Prognosis and long-term complications}

Schnitzler syndrome is a chronic condition, with only two patients documented to have achieved a spontaneous and sustained remission. ${ }^{3,44}$ However, a consensus statement from experts in the field suggested that it may be reasonable to stop therapy and observe patients if they achieved a complete remission and were on therapy for at least 2 years. ${ }^{5}$ In one large series of patients from a single institution, the median overall survival for the cohort was 12.8 years from the time of diagnosis. ${ }^{6}$ There are anecdotal reports of patients with Schnitzler syndrome who have refractory inflammatory anemia, developed reactive (AA) amyloidosis with nephrotic syndrome, ${ }^{4}$ pseudoxanthoma elasticum, ${ }^{45}$ nodular hyperplasia of the liver, ${ }^{46}$ antiphospholipid antibody syndrome, and hearing loss. The link between Schnitzler syndrome and some of these uncommon conditions is difficult to establish except 1) hearing loss that is a feature of Muckle-Wells and CINCA (chronic infantile neurological, cutaneous, and articular) syndromes that share features with Schnitzler and 2) AA amyloidosis. The incidence of AA amyloidosis due to a longstanding acute phase response in the untreated patient will hopefully be a thing of the past with faster recognition and prompt institution of therapy that rapidly controls the inflammation characteristic of this syndrome.

\section{Risk of lymphoma}

The initial series reported that perhaps $20 \%$ of patients may develop a lymphoproliferative disorder within 10 years of diagnosis. ${ }^{4,7}$ However, in a more recent series, the incidence of lymphoma was $12 \%$ with a median follow-up of 13 years from diagnosis. ${ }^{6}$ It is not known whether therapy with anakinra and good control of the inflammatory process is associated with a reduction in the risk of development of a lymphoproliferative disorder.

\section{Disclosure}

The authors report no conflicts of interest in this work.

\section{References}

1. Schnitzler L. Lesions urticaiennes chroniques permanentes (erytheme petaloide?) Cas cliniques, n 46 B. J Dermatol Angers. 1972. 
2. Schnitzler L, Schubert B, Boasson M, Gardaus J, Tourmen A. Urticaire chronique, lesions osseuses, macroglobulinemie IgM: maladie de Waldenstrom? 2 eme presentation. Bull Soc Fr Dermatol Syphil. 1974;81:363.

3. Lipsker D. The Schnitzler syndrome. Orphanet J Rare Dis. 2010;5:38

4. de Koning HD, Bodar EJ, van der Meer JW, Simon A. Schnitzler syndrome: beyond the case reports: review and follow-up of 94 patients with an emphasis on prognosis and treatment. Sem Arthritis Rheum. 2007;37:137-148.

5. Simon A, Asli B, Braun-Falco M, et al. Schnitzler's syndrome: diagnosis, treatment, and follow-up. Allergy. 2013;68:562-568.

6. Jain T, Offord CP, Kyle RA, Dingli D. Schnitzler syndrome: an underdiagnosed clinical entity. Haematologica. 2013;98:1581-1585.

7. Lipsker D, Veran Y, Grunenberger F, Cribier B, Heid E, Grosshans E. The Schnitzler syndrome. Four new cases and review of the literature. Medicine. 2001;80:37-44.

8. Kieffer C, Cribier B, Lipsker D. Neutrophilic urticarial dermatosis: a variant of neutrophilic urticaria strongly associated with systemic disease. Report of 9 new cases and review of the literature. Medicine. 2009;88:23-31.

9. Niederhauser BD, Dingli D, Kyle RA, Ringler MD. Imaging findings in 22 cases of Schnitzler syndrome: characteristic para-articular osteosclerosis, and the "hot knees" sign differential diagnosis. Skeletal Radiol. 2014;43:905-915.

10. Sokumbi O, Drage LA, Peters MS. Clinical and histopathologic review of Schnitzler syndrome: the Mayo Clinic experience (1972-2011). J Am Acad Dermatol. 2012;67:1289-1295.

11. Lebbe C, Rybojad M, Klein F, et al. Schnitzler's syndrome associated with sensorimotor neuropathy. J Am Acad Dermatol. 1994;30:316-318.

12. Nashan D, Sunderkotter C, Bonsmann G, Luger T, Goerdt S. Chronic urticaria, arthralgia, raised erythrocyte sedimentation rate and $\mathrm{IgG}$ paraproteinaemia: a variant of Schnitzler's syndrome? Br J Dermatol. 1995;133:132-134.

13. Kuenzli S, Buchet S, Saurat JH. Successful treatment of Schnitzler's syndrome with interferon alfa-2b. Dermatology. 2002;205:74.

14. De Waele S, Lecouvet FE, Malghem J, Jamar F, Lambert M. Schnitzler's syndrome: an unusual cause of bone pain with suggestive imaging features. AJR Am J Roentgenol. 2000;175:1325-1327.

15. Lecompte M, Blais G, Bisson G, Maynard B. Schnitzler's syndrome Skeletal Radiol. 1998;27:294-296.

16. Germain P, Fach J, Bui N, et al. Syndrome de Schnitzler: une cause rare d'urticaire systémique [Schnitzler syndrome: a rare cause of systemic urticaria]. Rev Med Interne. 2000;21:285-289. French.

17. Borradori L, Rybojad M, Puissant A, Dallot A, Verola O, Morel P. Urticarial vasculitis associated with a monoclonal IgM gammopathy: Schnitzler's syndrome. Br J Dermatol. 1990;123:113-118.

18. Yu JR, Leslie KS. Cryopyrin-associated periodic syndrome: an update on diagnosis and treatment response. Curr Allergy Asthma Rep. 2011; 11(1):12-20.

19. Hoffman HM, Mueller JL, Broide DH, Wanderer AA, Kolodner RD Mutation of a new gene encoding a putative pyrin-like protein causes familial cold autoinflammatory syndrome and Muckle-Wells syndrome. Nat Genet 2001;29:301-305.

20. de Koning HD, van Gijn ME, Stoffels M, et al. Myeloid lineage-restricted somatic mosaicism of NLRP3 mutations in patients with variant Schnitzler syndrome. J Allergy Clin Immunol. 2015;135:561-564.

21. Rowczenio DM, Trojer H, Russell $\mathrm{T}$, et al. Clinical characteristics in subjects with NLRP3 V198M diagnosed at a single UK center and a review of the literature. Arthritis Res Ther. 2013;15:R30.

22. Pizzirani C, Falzoni S, Govoni M, et al. Dysfunctional inflammasome in Schnitzler's syndrome. Rheumatology (Oxford). 2009;48: 1304-1308.

23. Volz T, Wolbing F, Fischer J, et al. Dermal interleukin-1 expression and effective and long-lasting therapy with interleukin-1 receptor antagonist anakinra in Schnitzler syndrome. Acta Derm Venereol. 2012;92:393-394.
24. Migliorini P, Del Corso I, Tommasi C, Boraschi D. Free circulating interleukin-18 is increased in Schnitzler syndrome: a new autoinflammatory disease? Eur Cytokine Netw. 2009;20:108-111.

25. Launay D, Dutoit-Lefevre V, Faure E, et al. Effect of in vitro and in vivo anakinra on cytokines production in Schnitzler syndrome. PLoS One. 2013;8:e59327.

26. Bhattacharyya J, Mihara K, Morimoto K, Takihara Y, Hide M. Elevated interleukin-18 secretion from monoclonal IgM+ B cells in a patient with Schnitzler syndrome. J Am Acad Dermatol. 2012;67: e118-e120.

27. Ryan JG, de Koning HD, Beck LA, Booty MG, Kastner DL, Simon A. IL-1 blockade in Schnitzler syndrome: ex vivo findings correlate with clinical remission. J Allergy Clin Immunol. 2008;121:260-262.

28. de Koning HD, Schalkwijk J, van der Meer JW, Simon A. Successful canakinumab treatment identifies IL-1beta as a pivotal mediator in Schnitzler syndrome. J Allergy Clin Immunol. 2011;128:1352-1354.

29. Krause K, Weller K, Stefaniak R, et al. Efficacy and safety of the interleukin-1 antagonist rilonacept in Schnitzler syndrome: an openlabel study. Allergy. 2012;67:943-950.

30. Lust JA, Lacy MQ, Zeldenrust SR, et al. Induction of a chronic disease state in patients with smoldering or indolent multiple myeloma by targeting interleukin $1 \beta$-induced interleukin 6 production and the myeloma proliferative component. Mayo Clin Proc. 2009;84:114-122.

31. Olsen E, Forre O, Lea T, Langeland T. Unique antigenic determinants (idiotypes) used as markers in a patient with macroglobulinemia and urticaria. Similar idiotypes demonstrated in the skin and on peripheral blood lymphocytes. Acta Med Scand. 1980;207:379-384.

32. Janier M, Bonvalet D, Blanc MF, et al. Chronic urticaria and macroglobulinemia (Schnitzler's syndrome): report of two cases. $J$ Am Acad Dermatol. 1989;20:206-211.

33. Ansell SM, Kyle RA, Reeder CB, et al. Diagnosis and management of Waldenstrom macroglobulinemia: Mayo stratification of macroglobulinemia and risk-adapted therapy (mSMART) guidelines. Mayo Clin Proc. 2010;85:824-833.

34. Asli B, Bienvenu B, Cordoliani F, et al. Chronic urticaria and monoclonal IgM gammopathy (Schnitzler syndrome): report of 11 cases treated with pefloxacin. Arch Dermatol. 2007;143:1046-1050.

35. Kastritis E, Katoulis A, Terpos E, Panayiotides I, Gavriatopoulopu M, Dimopopoulos MA. Schnitzler's syndrome: increased levels of bone formation and angiogenesis factors are reduced after successful pefloxacin treatment. Clin Lymphoma Myeloma. 2008;8:359-362.

36. Martinez-Taboada VM, Fontalba A, Blanco R, Fernandez-Luna JL. Successful treatment of refractory Schnitzler syndrome with anakinra: comment on the article by Hawkins et al. Arthritis Rheum. 2005;52: 2226-2227.

37. Gilson M, Abad S, Larroche C, Dhote R. Treatment of Schnitzler's syndrome with anakinra. Clin Exp Rheumatol. 2007;25:931.

38. Schuster C, Kranke B, Aberer E, Arbab E, Sturm G, Aberer W. Schnitzler syndrome: response to anakinra in two cases and a review of the literature. Int J Dermatol. 2009;48:1190-1194.

39. Cascavilla N, Bisceglia M, D'Arena G. Successful treatment of Schnitzler's syndrome with anakinra after failure of rituximab trial. Int J Immunopathol Pharmacol. 2010;23:633-636.

40. Frischmeyer-Guerrerio PA, Rachamalla R, Saini SS. Remission of Schnitzler syndrome after treatment with anakinra. Ann Allergy Asthma Immunol. 2008;100:617-619.

41. Neel A, Henry B, Barbarot S, et al. Long-term effectiveness and safety of interleukin-1 receptor antagonist (anakinra) in Schnitzler's syndrome: a French multicenter study. Autoimmun Rev. 2014;13:1035-1041.

42. Krause K, Feist E, Fiene M, Kallinich T, Maurer M. Complete remission in 3 of 3 anti-IL-6-treated patients with Schnitzler syndrome. J Allergy Clin Immunol. 2012;129:848-850.

43. Kyle RA, Durie BG, Rajkumar SV, et al. Monoclonal gammopathy of undetermined significance (MGUS) and smoldering (asymptomatic) multiple myeloma: IMWG consensus perspectives risk factors for progression and guidelines for monitoring and management. Leukemia. 2010;24:1121-1127. 
44. Asli B, Brouet JC, Fermand JP. Spontaneous remission of Schnitzler syndrome. Ann Allergy Asthma Immunol. 2011;107:87-88.

45. Machet L, Vaillant L, Machet MC, et al. Schnitzler's syndrome (urticaria and macroglobulinemia) associated with pseudoxanthoma elasticum. Acta Derm Venereol. 1992;72:22-24.
46. Lauwers A, Chouvy V, Mosnier JF, Misery L, Alexandre C. A case of Schnitzler's syndrome with nodular regenerative hyperplasia of the liver. Rev Rhum Engl Ed. 1999;66:281-283.

\section{Publish your work in this journal}

Pathology and Laboratory Medicine International is a peer-reviewed, open access journal focusing on innovative basic research and translational research related to pathology or human disease. The journal includes original research, updates, case reports, reviews and commentaries on current controversies. The Academic Sponsor of this journal is the Chinese American Pathology Association (CAPA). The manuscript management system is completely online and includes a very quick and fair peer-review system. Visit http://www.dovepress.com/testimonials.php to read real quotes from published authors.

Submit your manuscript here: http://www.dovepress.com/pathology-and-laboratory-medicine-international-journal 